\title{
Size distribution of two cross-cutting drumlin systems in northern Sweden: a measure of selective erosion and formation time length
}

\author{
Claas Hättestrand, Dermot Goodwillie, ${ }^{\dagger}$ Johan Kleman \\ Department of Physical Geography, Stockholm University, SE-106 91 Stockholm, Sweden
}

\begin{abstract}
Nearly 9000 individual lineations (drumlins and flutes) from two iceflow systems have been mapped over a $22500 \mathrm{~km}^{2}$ area of northern Sweden by interpretation of aerial photographs. The lineations were classified according to their size and orientation to allow a quantitative analysis of their distribution. The two glacial lineation systems, separated in time by at least 100000 years and two individual overriding ice sheets, cross-cut at a high angle. The older system occurs over the entire study area and is interpreted to have formed by prolonged sheet flow during Marine Isotope Stage 5d, while the youngest system is spatially restricted, marking the presence of a laterally constrained zone of faster ice flow, developed near the end of the last deglaciation. The effect of the younger ice flow was erosion and elimination of smaller lineations in the older system, while the larger drumlinoid forms survived more or less intact, thus creating an apparent increase in average drumlin size of the older lineation system. One possible explanation for the unaltered shape of these larger drumlins is that the glacier bed of the younger ice sheet only reached the pressure melting point in the lower parts of the terrain, thus eroding the smaller forms, while the larger forms protruded into colder parts of the ice mass and were protected from erosion and deformation. There was no evidence of the deformation of older drumlins into barchanoid shapes or the development of lee-side tail features on the distal side of pre-existing lineations, as has previously been described for crossing drumlin systems. The lack of any such deformational features suggests that the younger lineation system was formed by net erosion, rather than deformation or deposition.
\end{abstract}

\section{INTRODUCTION}

Glacial lineations, such as drumlins and flutings, are one of the most important tools for reconstructing former ice-sheet flow patterns (e.g. Boulton and others, 1985; Dyke and Prest, 1987; Boulton and Clark, 1990a, b; Kleman and others, 1997). By using information on the relative age in cross-cutting lineation swarms, glacial flow patterns from earlier (pre-deglaciation) ice-sheet configurations can also be inferred. Small-scale maps of glacial lineations that are used in such reconstructions, are nearly always generalized. That is, the symbols used do not represent the size and orientation of individual landforms, but are rather a representation of the general direction of a group of lineations, and mostly without respect to their size (e.g. Prest and others, 1968).

A few studies have addressed wet-based ice-flow interaction with and reshaping of pre-existing glacial landscapes of different properties. Boulton (1987) suggested that drumlins can be reshaped into ribbed (Rogen) moraine if overrun and partially destroyed by ice flow at a high angle to the ori-

$\dagger$ This work is based on a study made by D. Goodwillie during a one-semester visit to Stockholm University in the spring of 1996. He died in May 1997 at the age of 21. ginal ridge orientation. Lagerbäck and Robertsson (1988) and Clark (1993) have, by using examples from Fennoscandian and Canadian glacial geomorphology, shown another way of drumlin reshaping, where large pre-existing drumlins become more and more dissected and replaced by newly created small drumlins until final destruction. However, the orientation of the original landform is inherited as the new drumlins are placed in a string aligned with the former ice flow. Knight and McCabe (1997) also argued that barchan-shaped drumlins, found in Ireland and Keewatin, Canada, are formed when older lineations are cross-cut and reshaped by subsequent ice flow at a low angle.

Most of these studies have been at a landform scale rather than at a landscape or lineation swarm scale. Therefore, one of the primary aims of this study has been to map individual glacial lineations at a regional scale, in order to examine the variability and patterns of size distributions in different lineation swarms. An important question we address is: What can the physical parameters of cross-cutting lineation swarms tell about the mode and formation-time length of the different landform-creating events?

Northern Sweden is chosen as a study area (Fig. la and b) because of the availability of extensive cross-cutting drumlin swarms of widely different age. In addition, the general glacial history during the last glacial cycle of the area is relatively well-known through a large number of stratigraphical and geomorphological studies. 

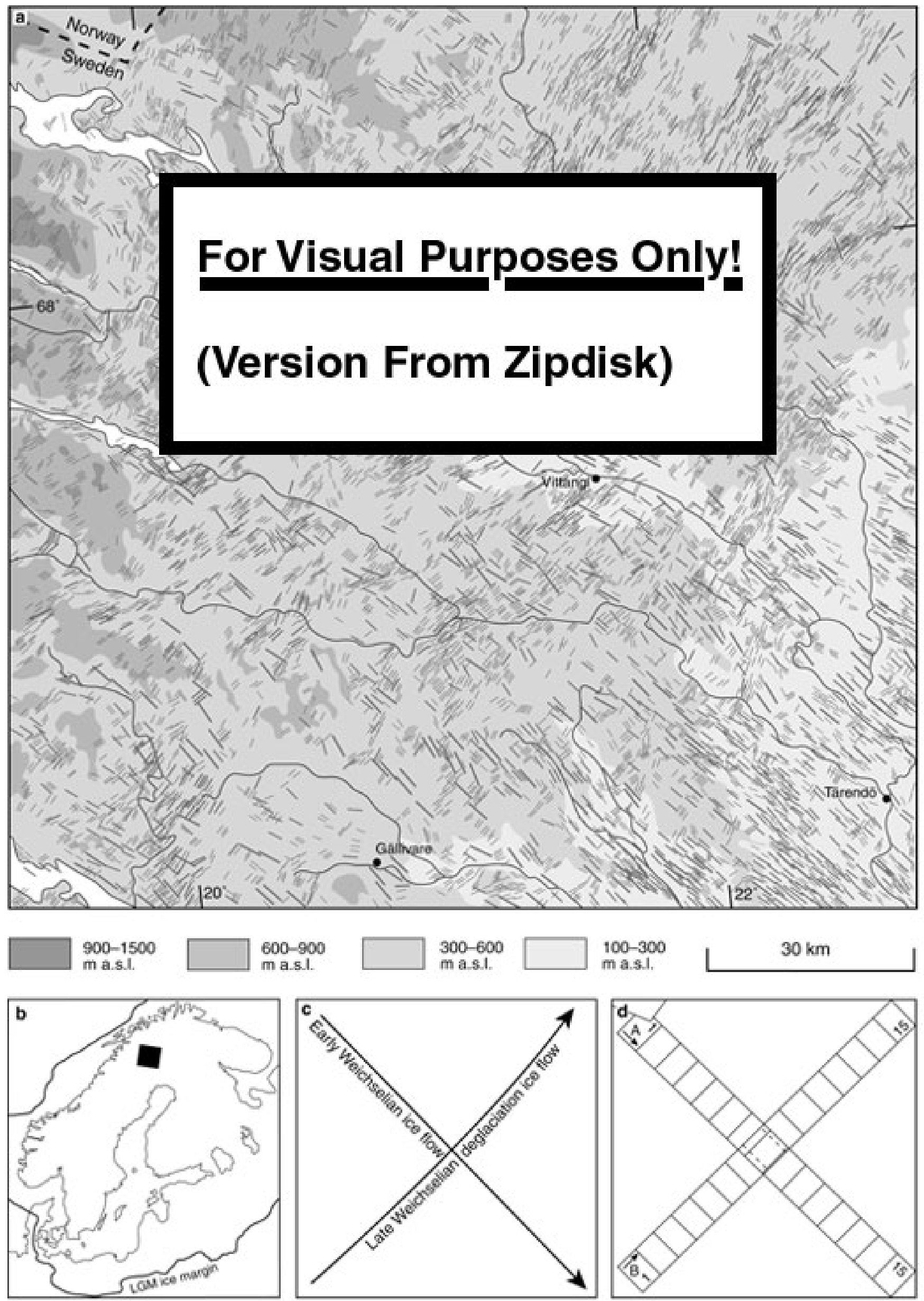

Fig. 1. (a) Till lineations divided by age (older-blue, younger-red) and size (small, medium, large) attributes. (b) Location map. (c) General ice-flow patterns. (d) Location of transects A and B in Figure 4. 


\section{PHYSICAL SETTING}

The topography of most of the study area is characterized by plains (200-500 $\mathrm{m}$ a.s.l.) with residual hills $(100-200 \mathrm{~m}$ high; Fig. la). The westernmost part borders the premontane region of the Scandinavian mountain range, with broad mountain plateaux around $800 \mathrm{~m}$ a.s.l. The highest peaks (in the northwest) reach $1200 \mathrm{~m}$ a.s.l. The residual hills in the central and eastern parts often constitute the proximal parts of large crag-and-tail ridges (Fig. 2).

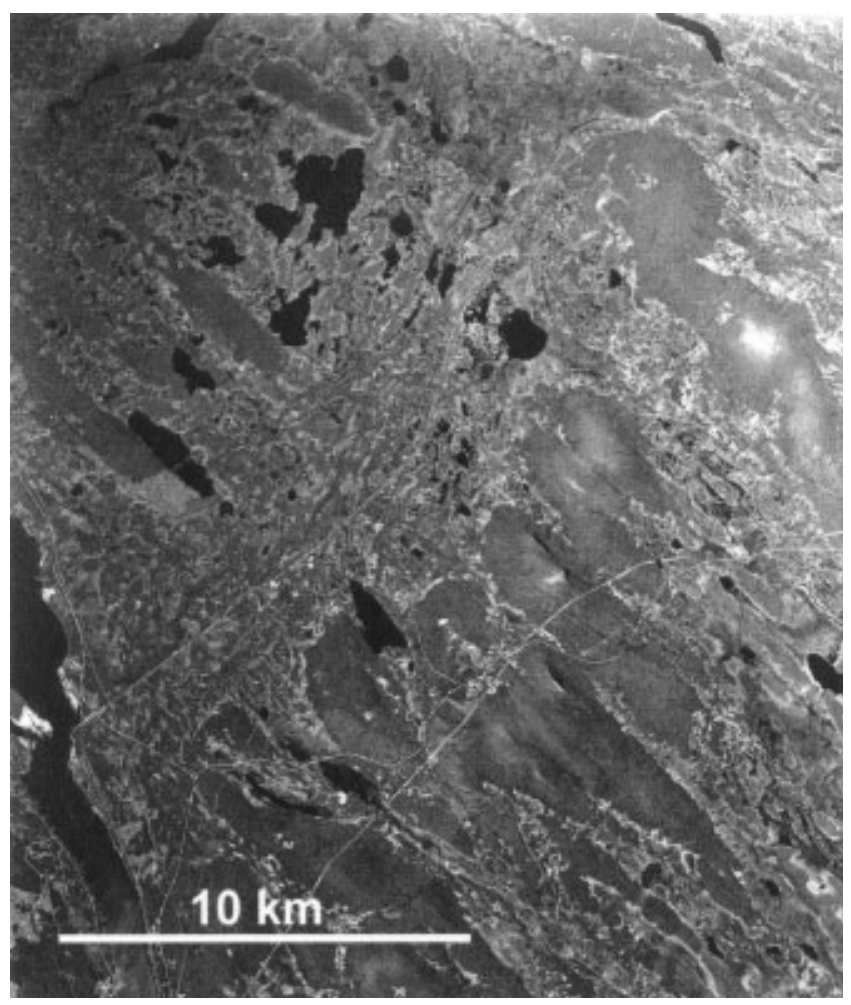

Fig. 2. Aerial photograph of lineations at Sjaunja, about $20 \mathrm{~km}$ west-southwest of Gällivare. The large-scale cragand-tail ridges in centre were formed by an early Weichselian ice flow from the northwest. Small SW lineations are located in the northwestern part of the photograph. North at top.

The glacial history of northern Sweden is relatively wellknown and both sediments and glacial-geomorphic elements from several glacial phases have been recorded (Fig. lc; Fagerlind, 1981; Nordkalott project, 1986a, b; Lagerbäck, 1988; Lagerbäck and Robertsson, 1988; Kleman, 1992; Hättestrand, 1998). The oldest glacial landform set (drumlins, eskers, Veiki moraine, end moraines, meltwater channels) document an ice-flow direction from the northwest and tentatively has been assigned to the first early Weichselian stadial (Marine Isotope Stage [MIS] 5d; Lagerbäck and Robertsson, 1988). However, Hättestrand (1998) has suggested that many of the large northwest-oriented drumlins may derive from even earlier ice-flow events. Overprinted on this flow system is a set of drumlins, ribbed moraines, eskers and meltwater channels indicating an ice flow from the southwest. This later flow system was formed during the last deglaciation (MIS 2/1; Lagerbäck and Robertsson, 1988). Within the central zone of enhanced ice flow from the southwest (Fig. 1), there is generally a $1-5 \mathrm{~m}$ layer of late-Weichselian till, whereas on either side of this zone the late-Weichselian till thickness is only 0-1 m (Nordkalott project, 1986d). These two ice-flow systems completely dominate the glacial geomorphology of the study area, although there are a few traces of additional intermediate ice-flow events (Lagerbäck and Robertsson, 1988; Kleman, 1992; Hättestrand, 1998). However, the general scarcity of landforms and sediments from intervening glacial events suggests the area was covered by cold-based ice during most of the main Weichselian glaciation (Lagerbäck and Robertsson, 1988; Kleman and others, 1997, 1999; Hättestrand, 1997, 1998).

\section{METHODS}

The data collection was conducted by interpretation of black and white aerial photographs at the scale of 1:150000. The potential geometric resolution of these photographs is about $4 \mathrm{~m}$ and, by using a Zeiss Jena Interpretoscope with 2-16x magnification, small-scale lineations (fluting) could be detected. To ensure data integrity, especially concerning the size attributes, all lineations were mapped twice. First, the lineations were mapped by their orientation. After the production of a complete picture of the size variations, the whole area was mapped a second time and each lineation was given a size attribute (small, medium or large).

The till lineations in Figures 1 and 3 are classified according to their direction (age) and size. At many locations, the two lineation systems cross-cut and, without exception, the northwest system is interpreted to be the oldest. When colour-coding the lineations in Figure la, we based the classification on continuity considerations, grouping together the lineations outlining a plausible ice-flow pattern (synchronous or time-transgressive). Therefore, each of the two systems may have considerable internal variability in orientation over the mapped area. In general, the older systems have orientations from the northwest-sector and the younger system from the southwest sector, and are hence called the NW-system and the SW-system. Deviations from these orientations mainly occur in the northwestern part of the map area, where the younger flow system indicates southerly or even south-southeasterly ice-flow directions. In cases of uncertainty, other directionally aligned geomorphological elements, such as eskers and meltwater channels, have been used to determine the system assignment.

One of the main aims of this study is to separate lineations of different size. Because there are almost 9000 lineations in the study area, an exact measurement of length, width and height for each lineation would be extremely time-consuming. Therefore, the size attribute given to each lineation is based on a visual estimate of the amount of material in the individual lineation, rather than specific length, width or height measures. An approximate figure of the dimensions of these classes is given in Table 1 (see also Fig. 2).

Table 1. Ranges for size classification of lineations

\begin{tabular}{lccc}
\hline Length & Width & Height \\
& $\mathrm{m}$ & $\mathrm{m}$ & $\mathrm{m}$ \\
\hline Small & $100-500$ & $10-50$ & $1-5$ \\
Medium & $500-1500$ & $50-300$ & $5-30$ \\
Large & $1500-8000$ & $300-1500$ & $30-200$ \\
\hline
\end{tabular}




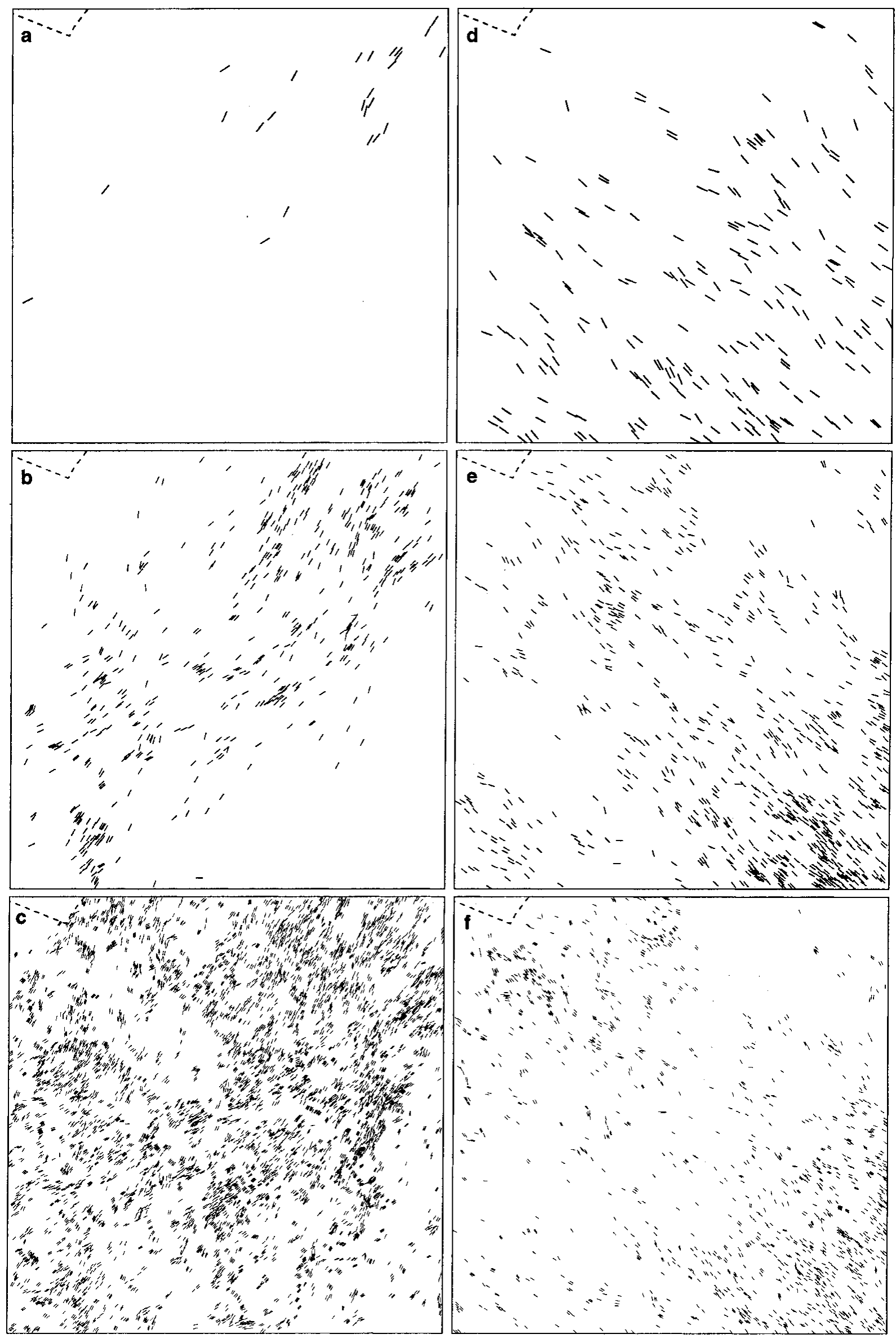

Fig. 3. Complete distribution record for each of the six lineation classes. (a) Large SW lineations. (b) Medium-sized SW lineations. (c) Small SW lineations. (d) Large NW lineations. (e) Medium-sized NW lineations. (f) Small NW lineations. Note the exclusive pattern for $(b)$ and $(f)$. 


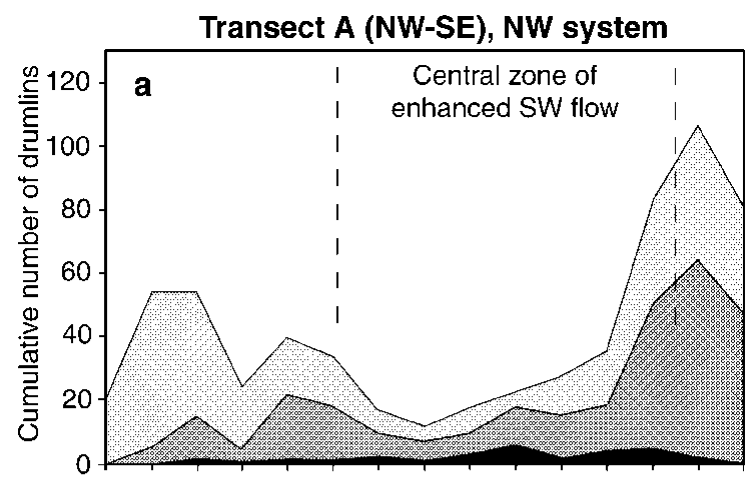

Transect A (NW-SE), SW system

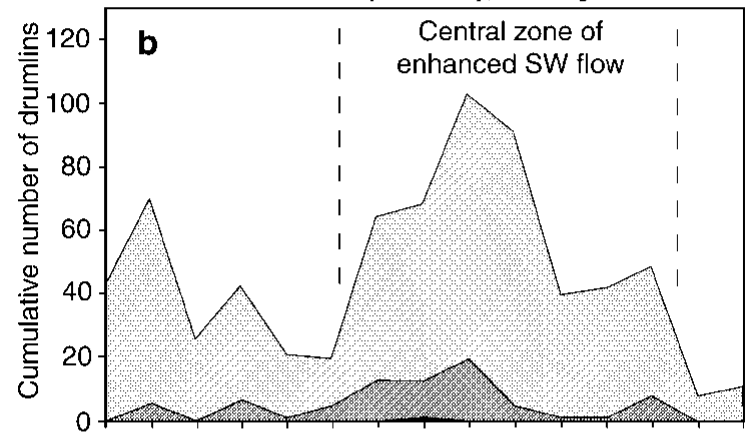

Transect B (SW-NE), NW system

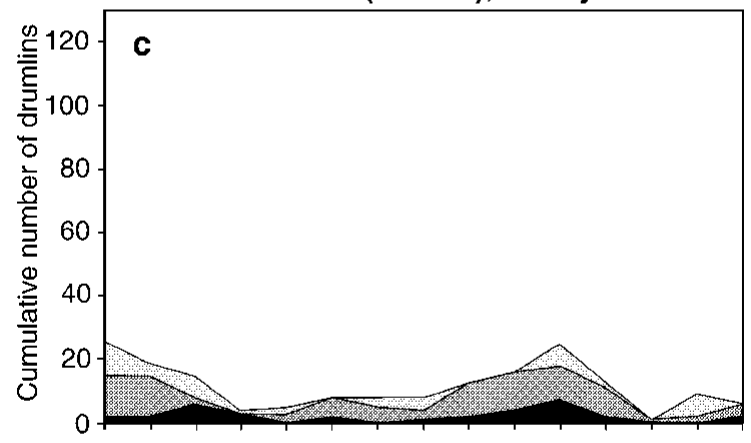

Transect B (SW-NE), SW system

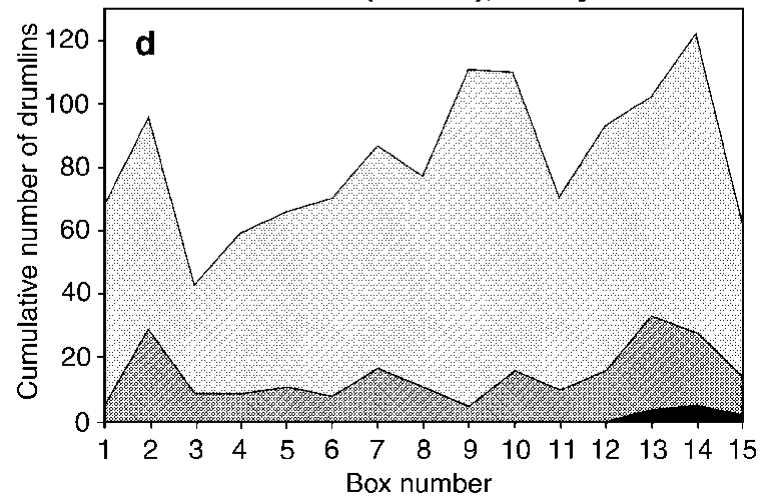

Small 20:

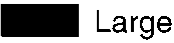

Fig. 4. Cumulative number of lineations in grids of transects $A$ and B. Graphs show statistics (a) along the NW flow, ( $b$ ) transverse to the $S W$ flow, (c) transverse to the $\mathcal{N W}$ flow, and $(d)$ along the $S W$ flow. The zone of laterally constrained enhanced SWflow is shown in ( $a$ ) and ( $b$ ).

The patterns of size variations are also illustrated in Figure 4. Two transects, each following the trend of the two systems (Fig. ld), were divided in 15 grids $(12.5 \times 17.75 \mathrm{~km})$. The number of lineations for each size and direction were counted within the grids and plotted against distance, both transverse and along the flow direction of each system.

\section{RESULTS: DISTRIBUTION OF TILL LINEATIONS}

In all, 8747 lineations were mapped. The distribution of these are shown in Figure la and in Table 2. Both the NW-system and the SW-system occur over the entire area, although they are unevenly distributed. The most striking irregularity is found in the southeastern corner of the area, where the $\mathrm{NW}$-system is denser and the $\mathrm{SW}$-system is represented only sparsely. The deficiency of SW-lineations here is obviously a primary pattern, in the sense that it represents a non-formation of lineations, because the SW direction is the last recorded ice flow in this area. The NW-system shows

Table 2. Number of lineations for each size and direction

\begin{tabular}{lrrrr}
\hline & \multicolumn{2}{c}{$\mathcal{N} W$-system } & \multicolumn{2}{c}{$S W$-system } \\
& Number & $\%$ & Number & $\%$ \\
& & & & \\
\hline & & & 5772 & 90.6 \\
Small & 1360 & 57.2 & 571 & 9.0 \\
Medium & 794 & 33.4 & 25 & 0.4 \\
Large & 225 & 9.5 & $\mathbf{6 3 6 8}$ & $\mathbf{1 0 0 . 0}$ \\
Total & $\mathbf{2 3 7 9}$ & $\mathbf{1 0 0 . 0}$ & & \\
\hline
\end{tabular}

increases in both the total number and size of lineations along its flow trend. This pattern also occurs less clearly in the SW-system.

When each of the size classes are viewed separately for the two systems (Fig. 3), more characteristics are revealed. The large- and medium-sized lineations of the SW-system clearly depict a laterally constrained zone of enhanced ice flow. It is likely this zone was constrained by areas that were dominated by cold-based conditions during deglaciation, as there are no topographic controls which can account for this pattern. However, the distribution of small lineations in the SW-system indicates no such clear zonation.

The NW-system shows other, and to some extent, exclusive patterns with respect to the SW-system (Fig. 4a and b). In the central part of the zone of enhanced SW flow, there is a clear deficiency of small NW lineations and a slight decrease in the number of medium NW lineations. However, there is no obvious decrease in the number of large lineations in this zone and, consequently, the apparent average size of the NW lineations increases in this zone.

Second-order irregularities are found in the distribution patterns of the two systems. These include "holes", i.e. minor areas $\left(<50 \mathrm{~km}^{2}\right)$ completely lacking lineations. These holes mostly coincide with topographic highs, where steeper slopes and a thinner debris layer (Nordkalott project, 1986c) probably suppressed lineation formation. However, it is also likely that many of these higher areas experienced cold-based conditions through much of the last glaciation and acted as sticky spots in an otherwise warm-based zone (Alley, 1993; Kleman and others, 1999). In addition, apparent deficiencies in the distribution of small lineations may be accounted for by the cover of lakes or overgrowth of Holocene peat layers; medium and large lineations are generally higher than the maximum peat thickness. 


\section{DISCUSSION}

From the distribution pattern of lineations in Figures la and 3 , we draw the conclusion that there was preferential erosion of smaller NW lineations during the subsequent SW flow, whereas the medium and large NW lineations were affected only to a minor degree. The alternative, that there was a predominance for formation of large NW lineations in a flow-transverse zone matching that of the later SW flow, seems highly unlikely, as the topography and geology is similar along the whole length of the NW flow in the study area. One possible explanation for the unaltered shape of the larger lineations is that the glacier bed of the younger ice sheet only reached the pressure melting point in the lower parts of the terrain. This would cause erosion of smaller and lower forms, while the larger forms, by their height, protruded into colder parts of the ice mass and were protected from erosion and deformation. Such an interpretation is supported by the fact that this area was most likely completely cold-based during the glacial maximum and successively thawed in places during deglaciation as a result of thinner ice, faster ice flow and a warming air temperature (Kleman and others, 1997, 1999; Hättestrand, 1997, 1998). However, many patches were cold-based up until final deglaciation and never thawed before they became ice free, particularly at higher elevations (Kleman and others, 1999). An alternative explanation is that the larger forms were indeed subject to the same alteration as the smaller forms, but again, by their size, this may be less obvious, as an amount of erosion or deposition that completely obliterates small forms may not significantly alter the general appearance of larger forms. We do not favour this explanation, as this would be expected to lead to a general remoulding of the larger forms, such as large NW lineations being overprinted or overlain by small SW lineations. However, there are relatively few examples of remoulding in the study area and most of the large NW lineations in the zone of enhanced SW flow lack overprinted SW lineations (Fig. la).

In the cases where the large NW lineations were affected by the SW-system, there is an overprint of surface striae, or flutings, on the crests of older lineations or on the tails of the large crag-and-tail ridges. We have not found any signs of deformation of older lineations into barchan-shaped drumlins or the development of lee-side tail features on the distal sides of pre-existing lineations. This indicates that the SW flow was dominated by erosional processes rather than deformation or deposition, as the latter processes would be expected to cause some younger, complete drumlins to be formed on top of the older forms.

The total number of lineations in the $\mathrm{SW}$-system is larger than in the NW-system (Table 2; Figs la and 3). This seems reasonable, as the SW-system was eroding many of the preexisting lineations, preferentially the small ones. Yet, the number of large lineations is about an order of magnitude higher in the NW-system. Even compared with the restricted zone of enhanced ice flow in the SW-system, there is still a much higher density of large lineations in the $\mathrm{NW}$-system. Whether formed by erosion, deformation, or deposition, of fundamental importance for lineation size is the flux of ice, i.e. the amount of ice passing over an area during formation (providing that the necessary prerequisites of sufficient sediment supply and wet-based conditions are met). Thus, a large average size of lineations in an area may be a result of either a long period of wet-based conditions and a persistent ice- flow direction, or an event of fast ice flow over the area, possibly during only a short time period. Ice flow from the southwest acted, as far as is known, only during the final stage of the last deglaciation and probably only for a few thousand years (Kleman, 1992; Kleman and others, 1997). Exactly how long the earlier NW flow persisted is uncertain. All lineations may have been created during the deglaciation of the first early Weichselian ice sheet. Alternatively, they may be the cumulative result of numerous glaciations of a magnitude comparable to the early Weichselian ice sheets (Hättestrand, 1998). The larger average size of the NWsystem may lend weight to the latter interpretation, especially since, according to global ice-volume records (e.g. Martinson and others, 1987), the deglaciation of the MIS $5 \mathrm{~d}$ ice sheets was as rapid as the last deglaciation. In addition, the NW-system shows no evidence of laterally constrained ice flow. In fact, this system of NW lineations is common throughout most of northern Sweden (Hättestrand, 1998), with very few directional deviations.

Therefore, our preferred interpretation is that the NWsystem was formed by a uniform sheet flow over the area during a relatively long time period, whereas the $\mathrm{SW}$-system represents a short event of enhanced ice flow in a laterally constrained corridor, with sluggish ice flow on either side. This pattern probably reflects the retreat of a zone of enhanced wet-based ice flow headward into a frozen-bed area of the ice sheet. On either side of this zone, the ice sheet thawed at its base only shortly before deglaciation, thus making it capable of producing only small lineations.

The increase in the total number of lineations, especially the large ones in the direction of ice flow for each system, may be explained in several ways. If the lineation swarm was created during headward retreat of a wet-based zone into a cold-based core of an ice sheet, the number and size of lineations may be linked to the period that a specific location experienced wet-based ice flow (i.e. the time between thawing of the glacier bed and deglaciation of that area). Based on the discussion above, we argue this is the case for the SW-system. Alternatively, if the lineations are created during more stable conditions (i.e. not during a deglaciation), the number and size of lineations may be related to the distance from the ice divide. Further from the ice divide, the ice velocity increases towards the equilibrium line and hence, more and larger lineations can be created. We interpret this to be the case for the NW-system.

\section{GONGLUSIONS}

In this study, we have shown that addressing size distributions while mapping glacial lineations helps to discern characteristic patterns of size and density variation, both within and between cross-cutting glacial landform swarms. Such characteristics may aid in interpreting the glaciodynamic conditions of the ice sheet that created them. Our study is spatially restricted, but if this method is used over larger areas, covering complete landform swarms, we believe it is possible to unravel more of the palaeoglaciology of formerly glaciated areas, especially older glacial events which predate and are overprinted by the last deglaciation ice flow.

\section{AGKNOWLEDGEMENTS}

This work was funded by grants toJ. Kleman from the Swedish 
Natural Science Research Council. We would like to thank D. J. A. Evans, R. C. A. Hindmarsh, and an anonymous referee for constructive comments and suggestions about the manuscript.

This paper is dedicated to Dermot Goodwillie. We miss him profoundly and express our deepest sympathy to his family.

\section{REFERENCES}

Alley, R. B. 1993. In search of ice-stream sticky spots. F. Glaciol., 39(133) 447-454.

Boulton, G. S. 1987. A theory of drumlin formation by subglacial sediment deformation. In Menzies, J. and J. Rose, eds. Drumlin Symposium. Rotterdam, A. A. Balkema, 25-80.

Boulton, G. S. and C. D. Clark. 1990a. A highly mobile Laurentide ice sheet revealed by satellite images of glacial lineations. Nature, 346(6287), 813-817.

Boulton, G. S. and C. D. Clark. 1990b. The Laurentide ice sheet through the last glacial cycle: the topology of drift lineations as a key to the dynamic behaviour of former ice sheets. Trans. R. Soc. Edinburgh, Ser. Earth Sci., $81(4), 327-347$

Boulton, G. S., G. D. Smith, A. S. Jones and J. Newsome. 1985. Glacial geology and glaciology of the last mid-latitude ice sheets. F. Geol. Soc., London, $142(3), 447-474$.

Clark, C. D. 1993. Mega-scale glacial lineations and cross-cutting ice-flow landforms. Earth Surf. Processes Landforms, 18(1), 1-29.

Dyke, A. S. and V. K. Prest. 1987. Late Wisconsinan and Holocene history of the Laurentide ice sheet. Géogr. Phys. Quat., 41 (2), 237-263.

Fagerlind, T. 1981. Glacial development in the Pajala district of northern Sweden. Sver. Geol. Unders., Ser. Ba 27.

Hättestrand, C. 1997. Ribbed moraines in Sweden — distribution pattern and paleoglaciological implications. Sediment. Geol., 111(1-4), 41-56.

Hättestrand, C. 1998. The glacial geomorphology of central and northern Sweden. Sver. Geol. Unders., Ser. Ca 85.
Kleman, J. 1992. The palimpsest glacial landscape in northwestern Sweden - Late Weichselian deglaciation landforms and traces of older west-centered ice sheets. Geogr. Ann., 74A (4), 305-325.

Kleman, J., C. Hättestrand, I. Borgström and A. Stroeven. 1997. Fennoscandian palaeoglaciology reconstructed using a glacial geological inversion model. f. Glaciol., 43(144), 283-299.

Kleman, J., C. Hättestrand and A. Clarhäll. 1999. Zooming in on frozenbed patches: scale-dependent controls on Fennoscandian ice sheet basal thermal zonation. Ann. Glaciol., 28 (see paper in this volume).

Knight, J. and A. M. McCabe. 1997. Drumlin evolution and ice sheet oscillations along the NE Atlantic margin, Donegal Bay, western Ireland. Sediment. Geol., 111(1-4), 57-72.

Lagerbäck, R. 1988. The Veiki moraines in northern Sweden — widespread evidence of an Early Weichselian deglaciation. Boreas, 17(4), 469-486.

Lagerbäck, R. and A.-M. Robertsson. 1988. Kettle holes - stratigraphical archives for Weichselian geology and palaeoenvironment in northernmost Sweden. Boreas, 17(4), 439-468.

Martinson, D. G., N. G. Pisias, J. D. Hays, J. Imbrie, T. C. Moore, Jr and N. J. Shackleton. 1987. Age dating and the orbital theory of ice ages: development of a high-resolution 0 to 300,000-year chronostratigraphy. Quat. Res., 27(1), 1-29.

Nordkalott Project. 1986a. Glacial geomorphology and paleohydrology, northern Fennoscandia. Scale 1:1000 000. Geological Surveys of Finland, Norway and Sweden. (Map of Quaternary Geology Sheet 2.)

Nordkalott Project. 1986b. Ice flow indicators, northern Fennoscandia. Scale 1:1000000. Geological Surveys of Finland, Norway and Sweden. (Map of Quaternary Geology Sheet 3.)

Nordkalott Project. 1986c. Quaternary deposits, northern Fennoscandia. Scale 1:1000000. Geological Surveys of Finland, Norway and Sweden. (Map of Quaternary Geology Sheet 1.)

Nordkalott Project. 1986d. Quaternary stratigraphy, northern Fennoscandia. Scale 1:1000 000. Geological Surveys of Finland, Norway and Sweden. (Map of Quaternary Geology Sheet 4.)

Prest, V. K., D. R. Grant and V. N. Rampton. 1968. Glacial map of Canada. Scale 1:5,000,000. Ottawa, Ont., Geological Survey of Canada. (GSC Map 1253A.) 